\title{
Imatinib Induced Delayed and Refractory Generalized Fluid Retention: A Case Report and Review of Literature
}

\author{
Bader A Abdelmaksoud ${ }^{1,2 *}$, Yaser Gad ${ }^{1,3}$ and Fayez G Alruwaily ${ }^{1}$ \\ ${ }^{1}$ King Abdulaziz Specialist Hospital, Sakaka, Aljouf, KSA \\ ${ }^{2}$ Department of Clinical Oncology, Faculty of medicine, Zagazig university Egypt
}

${ }^{3}$ Department of Pulmonology, Faculty of medicine, Asuit university, Egypt

*Corresponding author: Bader Abdelmaksoud, Department of Clinical Oncology, Faculty of Medicine, King Abdulaziz Specialist Hospital Egypt

\section{ARTICLE INFO}

Received: 蔧 June 06, 2019

Published: 些 June 20, 2019

Citation: Bader A A, Yaser Gad, Fayez G A. Imatinib Induced Delayed and Refractory Generalized Fluid Retention: A Case Report and Review of Literature. Biomed J Sci \& Tech Res 19(1)-2019. BJSTR. MS.ID.003233.
ABSTRACT

Imatinib is a tyrosine kinase inhibitor used mainly for ABL-BCR positive CML. Development of fluid retention(FR) following imatinib therapy is the most common side effect. However, sever FR as generalized anasarca, pleural effusion, ascites, and pericardial effusion are not common events during imatinib treatment. We report a case of CML treated with imatinib for long time then presented with sever generalized FR. After exclusion of other causes of generalized FR we stop imatinib but there was no improvement of the conditions. So, mild FR resulted from imatinib may pass to chronic state and become refractory to treatment and should be treated as early as possible.

Keywords: Imatinib; FR; CML; Tyrosine Kinase Inhibitors; BCR-ABL; CD117

Abbreviations: FR: Fluid Retention; CML: Chronic Myeloid Leukemia; GIST: Gastrointestinal Stromal Tumor; LLs: Lower Limbs; FR: Fluid Retention; CR: Complete Response

\section{Introduction}

The molecular targeted therapy started with introduction of tyrosine kinase inhibitor (Imatinib) that selectively inhibit phosphorylation of BCR-ABL protein with subsequent inhibition of growth of BCR-ABL positive cells [1]. Imatinib was approved in 2001 as a first targeted therapy for treatment of BCR-ABL positive chronic myeloid leukemia (CML) and in 2003 for treatment of ckit or CD 117 positive gastrointestinal stromal tumor (GIST) [2,3]. The safety and efficacy profiles of imatinib were explored in the last decades and have been well known, the most common reported side effect and dose limiting toxicity of imatinib was fluid retention (FR) [4]. Manifestations of FR usually presented as mild periorbital and/or lower limbs (LLs) edema that was easily manageable [5]. Development of sever FR manifested by marked subcutaneous and LLs edema, ascites, pleural and pericardial effusions were less frequently seen with imatinib treatment [6]. Due to rarity of imatinib induced sever FR, we reported this case of imatinib induced marked FR presented after long time of imatinib treatment and was refractory to drug withdrawal and conventional treatment.

\section{Case Report}

A 88-years old female with remarkable history for diabetes, ischemic heart disease, known case of CML for which she received imatinib for more than 10 years and still under treatment. This patient presented with two weeks history of gradually progressive breathlessness, mild cough associated with LL swelling and not associated with fever. The patient came to emergency department where ECG and echocardiography were normal apart from mild to moderate pericardial effusion, X-ray chest showed bilateral moderate pleural effusion (Figure 1) then patient was admitted for further evaluation and management. We asked for full investigations, CT chest showed moderate bilateral effusion more in the left side (Figure 2A) with mild pericardial effusion (Figure 2B), abdomino-pelvic ultrasound showed normal abdominal and pelvic organs with moderate free fluid in abdomen and pelvis, complete blood count, renal function tests, liver function tests and serum electrolytes are all within normal limits. Aspiration of both ascetic and pleural fluids was done and subjected to chemical, 
microbiological and cytological analysis which showed features of transudate with no growth of any organism. So based on history, clinical examination and investigations, all causes of generalized edema were excluded and the only explanation for development of this generalized FR was imatinib use. As the patient was in hematological and molecular complete response(CR) for last year, we stopped the imatinib and the patient was followed and treated symptomatically. We expected that the conditions of the patient will improved after imatinib withdrawal and diuretics, but there is no improvement after more than 3 weeks of stoppage of imatinib.

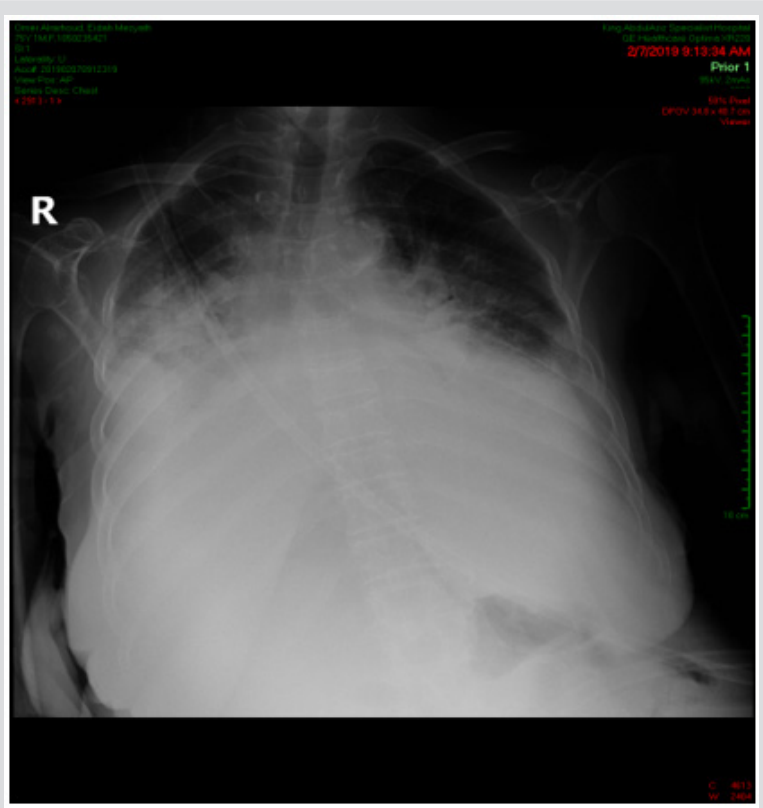

Figure 1: Plain X-ray chest showed bilateral pleural effusion.

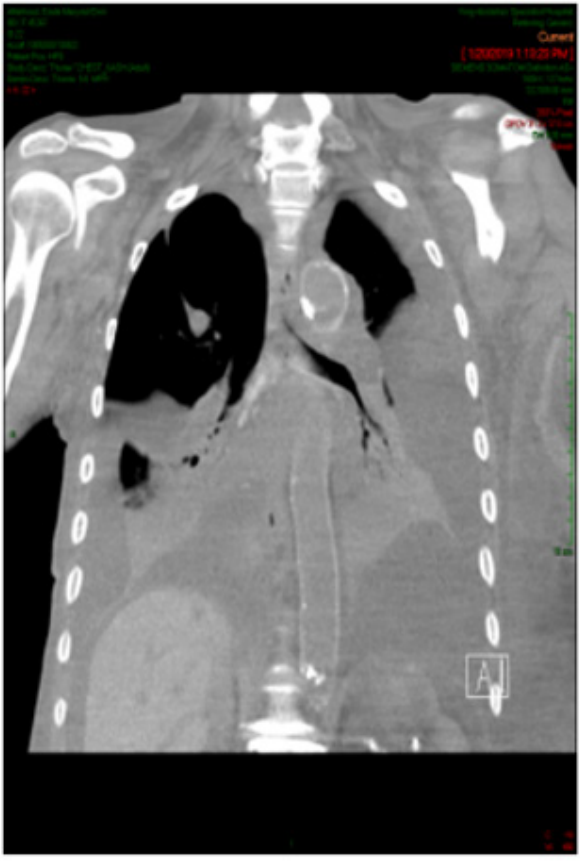

(A)

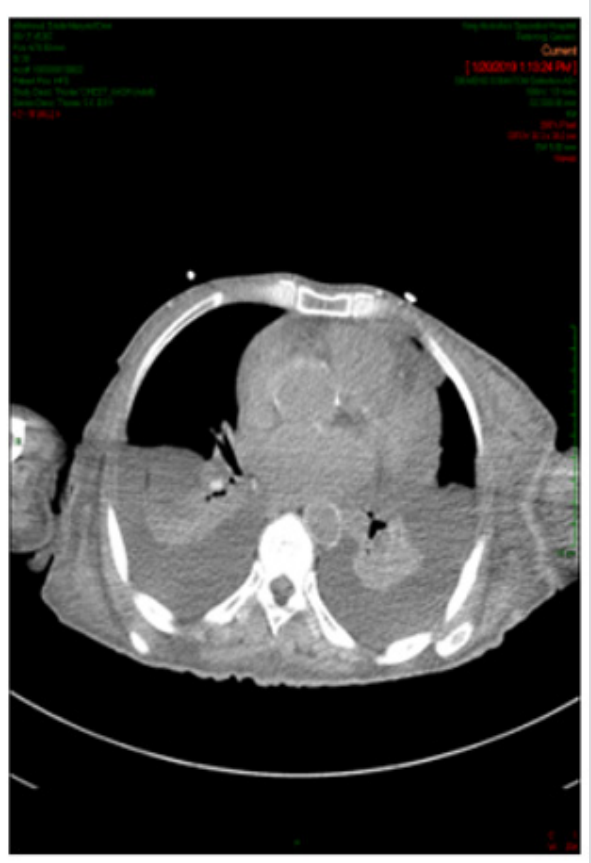

(B)

Figure 2: (A): CT chest showed bilateral pleural effusion more in the Lt side, (B): With minimal pericardial effusion.

\section{Discussion}

CML is a myeloproliferative disorder of hematopoietic stem cells with 1.5 per 100,000 population incidence rate every year in US and accounted for about $15 \%$ of all leukemia's in adults [7].
The pathognomonic diagnosis of CML is established by presence of Philadelphia chromosome which resulted from reciprocal translocation $(\mathrm{t} 9,22)$ to form ABL-BCR signal transduction tyrosine kinase protein [8]. Treatment of CML was revolutionized after development of imatinib which remain the 1st line therapy in all 
newly diagnosed CML [9], however, development of adverse effects of imatinib was observed and resulted sometimes in dose reduction or drug interruption. The course of imatinib associated FR usually developed acutely after short duration of drug administration and known as acute or progressive form or developed after longer duration of treatment and named intermittent or steady course characterized by chronic and persistent fluid accumulation [5]. Various studies reported long-term adverse effects of imatinib as cardiac toxicities, myositis, renal failure, secondary malignancy, multiple sclerosis, dermatitis, gynecomastia, pancreatitis, hypogammaglobulinemia, hypophosphatemia, opportunistic infections, cerebral edema, although some authors reported generalized edema in less than $10 \%$ of cases as a short term toxicities not long-term as in our study [10]. In most of case reports, the occasional or unusual forms of FR due to imatinib therapy usually resolved and improved after discontinuation of the drug [11]. However, in our case the condition not improved after imatinib cessation that we considered it as a prolonged refractory FR state.

Our explanation was that old age with presence of some comorbidities might be the aggravating factors for this prolonged and persistence of FR. Although chronic and prolonged generalized FR is unusual adverse effect of imatinib therapy, this case report should raise this issue for physician to be cautious during treating patients with imatinib and expect that FR may develop even after long-term duration specially if there is aggravating factors that trigger fluid retention and accumulation in the body elsewhere. Also, chronic mild FR either localized or generalized might progressed to refractory state not responding to cessation of the drug and diuretics. So, this case should raise the question for the need of more advanced monitoring systems either radiologically or sonographically to evaluate the cases under imatinib treatment periodically during the hall course of treatment and do not exclude the cases with long-term therapy not get FR as this side effect may develop at any time with mild form pass to chronic state that may not respond to treatment.

\section{Conclusion}

Imatinib induced FR retention is the most common adverse effect seen and account for some bothersome in patients with CML specially those with prolonged treatment course, although most cases showed mild degree of FR even those developed acute state of FR respond very well to diuretics along with either dose reduction or temporary dose drug cessation. However, in this report, stoppage of drug and other conventional measures failed to improve the conditions due to presence of confounding reasons that lead to chronic accumulation of the fluids. So our recommendation for physician prescribing imatinib should be cautious and attentive for development of delayed and refractory FR which may be preventable from the start.

\section{Conflict of Interest}

All authors declared there is no conflict of interest.

\section{References}

1. Banka R, Udwadia Z (2017) Imatinib-induced pleural effusion: A case report. J Postgrad Med 63(1): 55-57.

2. Siddiqui MA, Scott LJ (2007) Imatinib. A review of its use in the management of gastrointestinal stromal tumours. Drugs 67(5): 805-20.

3. Fausel C (2007) Targeted chronic myeloid leukemia therapy: Seeking a cure. Am J Health Syst Pharm 64(24): 15: 9-15.

4. Kim KW, Shinagare AB, Krajewski KM, Pyo J, Tirumani SH, et al. (2015) Fluid Retention Associated with Imatinib Treatment in Patients with Gastrointestinal Stromal Tumor: Quantitative Radiologic Assessment and Implications for Management. Korean J Radiol 16(2): 304-313.

5. Blanke CD, Rankin C, Demetri GD, Ryan CW, Von Mehren M, et al. (2008) Phase III randomized, intergroup trial assessing imatinib mesylate at two dose levels in patients with unresectable or metastatic gastrointestinal stromal tumors expressing the kit receptor tyrosine kinase: S0033. J Clin Oncol 26(4): 626-632.

6. Verweij J, Van Oosterom A, Blay JY, Judson I, Rodenhuis S, et al. (2003) Imatinib mesylate (STI-571 Glivec, Gleevec) is an active agent for gastrointestinal stromal tumours, but does not yield responses in other soft-tissue sarcomas that are unselected for a molecular target. Results from an EORTC Soft Tissue and Bone Sarcoma Group phase II study. Eur J Cancer 39(14): 2006-2011.

7. Masiello D, Gorospe G, Yang AS (2009) The occurrence and management of fluid retention associated with TKI therapy in CML, with a focus on dasatinib. J Hematol Oncol 2: 46.

8. Bartram CR, De Klein A, Hagemeijer A, Van Agthoven T, Geurts Van Kessel A, et al. (1983) Translocation of c-ab1 oncogene correlates with the presence of a Philadelphia hromosome in chronic myelocytic leukaemia. Nature 306(5940): 277-280.

9. Kantarjian HM, Talpaz M, Giles F, Obrien S, Cortes J (2006) New insights into the pathophysiology of chronic myeloid leukemia and imatinib resistance. Ann Intern Med 145(12): 913-923.

10. Mughal TI, Schrieber A (2010) Principal long-term adverse effects of imatinib in patients with chronic myeloid leukemia in chronic phase. Biologics: Targets \& Therapy 4: 315-323.

11. Pinilla Ibarz J, Cortes J, Mauro MJ (2011) Intolerance to tyrosine kinase inhibitors in chronic myeloid leukemia: definitions and clinical implications. Cancer 117(4): 688-697. 
ISSN: 2574-1241

DOI: 10.26717/BJSTR.2019.19.003233

Bader A Abdelmaksoud. Biomed J Sci \& Tech Res

(C) (9) This work is licensed under Creative BY Commons Attribution 4.0 License

Submission Link: https://biomedres.us/submit-manuscript.php

\begin{tabular}{ll} 
BIOMEDICAL & \multicolumn{1}{c}{ Assets of Publishing with us } \\
RESEARCHES & - Global archiving of articles \\
& - Immediate, unrestricted online access \\
& - Rigorous Peer Review Process \\
\end{tabular}

